\title{
Physical inactivity as a risk factor for all- cause mortality in Brazil (1990-2017)
}

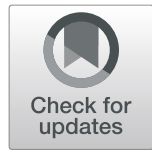

\author{
Diego Augusto Santos Silva ${ }^{1 *}$ (D), Mark Stephen Tremblay², Fatima Marinho ${ }^{3}$, Antonio Luiz Pinho Ribeiro ${ }^{4}$, \\ Ewerton Cousin ${ }^{5}$, Bruno Ramos Nascimento ${ }^{6}$, Paulo da Fonseca Valença Neto ${ }^{3}$, Mohsen Naghavi ${ }^{7}$ and \\ Deborah Carvalho Malta ${ }^{4}$
}

\begin{abstract}
Background: The aim of this study was to estimate the mortality from all causes as a result of physical inactivity in Brazil and in Brazilian states over 28 years (1990-2017).

Methods: Data from the Global Burden of Disease (GBD) study for Brazil and states were used. The metrics used were the summary exposure value (SEV), the number of deaths, age-standardized mortality rates, and the fraction of population risk attributable to physical inactivity.

Results: The Brazilian population presented risk of exposure to physical inactivity of (age-standardized SEV) of 59\% (95\% U.I. 22-97) in 1990 and 59\% in 2017 (95\% U.I. 25-99). Physical inactivity contributed a significant number of deaths $(1990,22,537,95 \%$ U.I. 12,157-34,745; 2017, 32,410, 95\% U.I. 17,976-49,657) in the analyzed period. These values represented mortality rates standardized by age (per 100,000 inhabitants) of 31 (95\% U.I. 17-48) in 1990 and 15 (95\% U.I. 8-23) in 2017. From 1990 to 2017, a decrease in standardized death rate from all causes attributable to physical inactivity was observed in Brazil (- 52\%, 95\% U.I. -54 to -49$)$. The Brazilian states with better socioeconomic conditions presented greater reductions in age-standardized mortality (male: $r h o=0.80$; female: rho 0.84) over the period of 28 years.
\end{abstract}

Conclusions: These findings support the promotion of physical activity in the Brazilian population for the prevention of early mortality.

Keywords: Adults, Epidemiology, Disease burden, Physical activity, Morbidity

\section{Background}

Physical inactivity is associated with the early onset of noncommunicable chronic diseases that lead to health problems and to all-cause mortality, regardless of other risk factors [1-3]. This relationship has been researched since the 1950s [4] and makes physical inactivity one of the main modifiable health risk factors in all age groups.

\footnotetext{
* Correspondence: diegoaugustoss@yahoo.com.br

${ }^{1}$ Physical Education Department, Research Center in Kinanthropometry and Human Performance, Federal University of Santa Catarina, Trindade, Florianopolis, SC 88040-900, Brazil

Full list of author information is available at the end of the article
}

Data from the Global Burden of Disease (GBD) study revealed that physical inactivity was risk factor accounting for approximately 1.3 million deaths (17 deaths per 100,000 inhabitants) in individuals aged 25 years and over [5]. These alarming data combined with a number of systematic reviews and meta-analyses that highlighted physical inactivity as a pandemic $[6,7]$ supported the publication of the World Health Organization Global Plan of Action for Physical Activity 2018-2030 [8]. This document aims to provoke a relative reduction in physical inactivity of $10 \%$ by 2025 and of $15 \%$ by 2030 [8], which will contribute to a longer life expectancy of the population $[1,8]$. 
The estimate of the association between physical inactivity and all-cause mortality among the Brazilian population is not known. To date, what has been reported for Brazil are estimates of physical inactivity and all-cause mortality from a single year [9] and from a single city in the country [10]. This information is important but does not allow the analyses of trend indicators of all-cause mortality as a result of physical inactivity. Thus, the present study will contribute new, important, and timely evidence related to this subject.

The present study aims to analyze the temporal evolution (1990 to 2017) of mortality rates for all causes attributable to physical inactivity in Brazil and in Brazilian states.

\section{Methods}

\section{General aspects}

An analytical study based on estimates of global burden of disease for Brazil made by GBD 2017 was carried out, coordinated by the Institute for Health Metrics and Evaluation (IHME) in partnership with the Ministry of Health of Brazil [11-15]. In the analysis of mortality, information from the Mortality Information System of the Brazilian Ministry of Health was used, with adjustment for underreporting of deaths and declaration of undefined/nonspecific causes, called garbage codes [13-15].

The standardized methodology of analysis adopted by the GBD makes it possible to compare countries, regions, and subnational data, also enabling analyzing trends, provided that the time series data are adjusted and comparable [13-15].

\section{Mortality estimate due to diseases that have physical inactivity as risk factor}

In the present study, physical inactivity was considered a risk factor for breast cancer, colorectal cancer, ischemic heart disease, diabetes mellitus, and stroke [5]. Other causes of mortality that have physical inactivity as one of the risk factors were not determined in the GBD study methodology. Information on the records and how each of these diseases was collected, estimated, and adjusted are found elsewhere in the literature [5, 13-15].

The comparative risk assessment conceptual framework used in GBD study established a causal web of hierarchically organized risks or causes that contribute to health outcomes, which allows for quantification of risks or causes at any level in the framework [5]. In GBD 2017, as in previous iterations of the GBD study, we evaluated a set of behavioral, environmental and occupational, and metabolic risks, where risk-outcome pairs were included based on evidence rules [5]. These risks were organized in four hierarchical levels, where level 1 represents the overarching categories (behavioral, environmental and occupational, and metabolic) nested within level 1 risks; level 2 contains both single risks and risk clusters; level 3 contains the disaggregated single risks from within level 2 risk clusters; and level 4 details risks with the most granular disaggregation. Physical inactivity is in the category of behavioral risk factor and stands out at hierarchical level 2 [5]. In addition, physical inactivity does not have any level of disaggregation.

\section{Physical inactivity prevalence estimate}

Surveys of the general adult population performed using random sampling procedures that assessed self-reported physical activity in all life domains (leisure/recreation, work, household, and transport) were included. Studies that evaluated only one of the physical activity domains were not included [5].

In general, for GBD estimates, data are primarily derived from two questionnaires, the Global Physical Activity Questionnaire (GPAQ) and the International Physical Activity Questionnaire (IPAQ). However, other studies that evaluated physical activity intensity, frequency, and duration in all domains were included [5].

In the case of Brazil, surveys considered included the National Health Survey 2013, Surveillance System for Risk Factors and Protection for Chronic Diseases by Telephone Inquiry (VIGITEL), Household Survey on Risk Behaviors and Referred Morbidity of Noncommunicable Diseases 2002-2005, World Health Survey 2003, and the International Study on the Prevalence of Physical Activity. Further details can be found at http://ghdx. healthdata.org/gbd-2016/data-input-sources?locations= $135 \&$ components $=6 \&$ risks $=125$.

To standardize all physical inactivity estimates in Brazil, data from the population aged 25 years or more were considered. Physical activity was considered only when accumulated for at least 10 consecutive minutes or more. Physical activity frequency, duration, and intensity were used to calculate the total metabolic equivalent (MET) minutes in the week. Physical activity level was categorized by total MET-minutes per week. The lower limit (600 MET-min/week) is the recommended minimum amount of physical activity to get any health benefit $[5,16]$. More details on these models can be found in the literature [5].

\section{Analysis strategy}

The contribution of physical inactivity to mortality from all causes investigated in this study was estimated using a conceptual framework of the comparative risk factor assessment [5]. For this, the CODEm simulation model, which is an analytical tool that tests various statistical models of causes of death and creates a combination of models that provide the best predictive performance, was used to estimate indicators by sex, age, state, year, 
and cause. The DisMod-MR 2.1 software (World Health Organization $\odot$, Geneva, Switzerland), a meta-regression tool, was used to simultaneously derive estimates of prevalence, disability, and mortality due to physical inactivity [5]. Spatiotemporal Gaussian process regression (ST-GPR) has been used for risk factors where the data density is sufficient to estimate a very flexible time trend. The approach is a stochastic modelling technique that is designed to detect signals amidst noisy data. It also serves as a powerful tool for interpolating non-linear trends. Unlike classical linear models that assume that the trend underlying data follows a definitive functional form, GPR assumes that the specific trend of interest follows a Gaussian process. Details of all models can be found in literature [5].

In this study, the counterfactual level of risk exposure used is the risk exposure that is both theoretically possible and minimizes risk in the exposed population that consequently captures the maximum population attributable burden [5]. For each risk evaluated in GBD study, included low physical activity, has been used the best available epidemiological evidence from published and unpublished relative risks by level of exposure and the lowest observed level of exposure from cohorts used to select a single level of risk exposure combined to establish the theoretical minimum-risk exposure level (TMREL) [5]. The TMREL for physical activity is 3000-4500 MET-min per week, which was calculated as the exposure at which minimal deaths across outcomes occurred [5].

We also estimated the population attributable fraction (PAF), which represents the proportion of risk that would be reduced in a given year if the exposure to a risk factor in the past was reduced to an ideal exposure scenario [5]. We used a recently published doseresponse meta-analysis of prospective cohort studies to estimate the effect size of the change in physical activity level on breast cancer, colon cancer, diabetes, ischemic heart disease, and ischemic stroke [3].

Summary exposure value (SEV) for physical inactivity was used in this study. SEV is the relative riskweighted prevalence of exposure, a univariate measure of risk-weighted exposure, taking the value zero when no excess risk for a population exists and the value one when the population is at the highest level of risk. We report SEVs on a scale from 0 to $100 \%$ where a decline in SEV indicates reduced exposure to physical inactivity and an increase in SEV indicates increased exposure. More details on SEV are also available elsewhere $[5,13-15]$.

The absolute numbers of deaths and mortality rates (per 100,000 inhabitants, crude, and age-standardized) were also used as metrics [5, 13-15]. In addition, the 95\% uncertainty intervals were estimated (95\% U.I.).
Analyses were performed for the Brazilian population and also stratified by sex and age (25-49 years, 50-69 years, 70+ years). Analyses were presented for each of the Brazilian states plus the Federal District in the years of 1990 and 2017. The GBD study created the Socioeconomic Development Index (SDI) [13-15] for all evaluated locations, by calculating per capita income, formal education at 15 years of age, and fertility rate. This index was used to compare the metrics among Brazilian states. For this, the Spearman correlation coefficient was applied.

\section{Results}

The Brazilian population presented risk of exposure to physical inactivity of (age-standardized SEV) 59\% (95\% U.I. 22-97) in 1990 and 59\% in 2017 (95\% U.I. 25-99). These values represented a stability of the Brazilian population in the exposure to physical inactivity over 28 years. All the Brazilian states presented this stability in the age-standardized SEV from 1990 to 2017 (data not shown in the tables/figures).

In Brazil, it was estimated that 22,537 (95\% U.I. 12, 157-34,745) deaths from all causes were attributable to physical inactivity in 1990. In 2017, 32,410 (95\% U.I. 17, 976-49,657) deaths were estimated from all causes attributable to physical inactivity. These values represented mortality rates standardized by age (per 100,000 inhabitants) of 31 (95\% U.I. 17-48) in 1990 and 15 (95\% U.I. 8-23) in 2017. From 1990 to 2017, a decrease in standardized death rate from all causes attributable to physical inactivity was observed in Brazil (- 52\%, 95\% U.I. - 54 to - 49). From 1990 to 2017, the Brazilian states with the highest percentage reductions in agestandardized mortality rate for all causes attributable to physical inactivity were Espírito Santo (- 64\%, 95\% U.I.: - 67 to - 60), Paraná (-60\%, 95\% U.I. - 62 to - 57), and São Paulo (-60\%, 95\% U.I. -62 to -57$)$. Table 1 shows information on all-cause deaths attributable to physical inactivity per Brazilian state in 1990 and 2017.

The age-standardized mortality rate (per 100,000 population) for all causes attributable to physical inactivity in 1990 and 2017 in the Brazilian male population was 34 (95\% U.I. 18-53) and 17 (95\% U.I. 09-27), respectively. In 2017, there was a significant reduction compared to 1990 in age-standardized mortality rate for all causes attributable to physical inactivity in males from all Brazilian states. While in 1990, the highest agestandardized mortality rates for all causes attributable to physical inactivity were observed in men from the Southern and Southeastern states of Brazil; in 2017, the highest age-standardized mortality rates for all causes attributable to physical inactivity were observed in males from the North and Northeast of Brazil (Fig. 1). 
Table 1 Number and age-standardized mortality rate for all-causes in Brazil in ages $\geq 25$ years

\begin{tabular}{|c|c|c|c|c|c|c|c|c|c|c|c|c|c|c|c|}
\hline \multirow[b]{4}{*}{ Brazil } & \multicolumn{15}{|c|}{ Mortality for all-causes ${ }^{\dagger}$ due to physical inactivity } \\
\hline & \multirow{3}{*}{$\begin{array}{l}1990 \\
\text { Deaths } \\
22,537\end{array}$} & & & \multirow{3}{*}{$\begin{array}{l}2017 \\
\text { Deaths } \\
32,410\end{array}$} & & & 1990 & & & 2017 & & & Chang & $(1990-2$ & 017) \\
\hline & & \multicolumn{2}{|c|}{ 95\% U.I. } & & \multicolumn{2}{|l|}{ 95\% U.I. } & \multirow{2}{*}{$\frac{\text { Rate }^{*}}{31}$} & \multicolumn{2}{|c|}{ 95\% U.I. } & \multirow{2}{*}{$\begin{array}{l}\text { Rate* }^{*} \\
15\end{array}$} & \multicolumn{2}{|c|}{ 95\% U.I. } & \multirow{2}{*}{$\begin{array}{l}\% * \\
-52\end{array}$} & \multicolumn{2}{|c|}{ 95\% U.I. } \\
\hline & & 12,157 & 34,745 & & 17,976 & 49,657 & & 17 & 48 & & 08 & 23 & & -54 & -49 \\
\hline Acre & 32 & 17 & 49 & 66 & 36 & 101 & 24 & 13 & 38 & 13 & 07 & 19 & -48 & -52 & -43 \\
\hline Alagoas & 311 & 170 & 481 & 510 & 286 & 775 & 26 & 14 & 39 & 17 & 10 & 26 & -32 & -38 & -25 \\
\hline Amapá & 17 & 09 & 27 & 51 & 29 & 77 & 24 & 13 & 36 & 13 & 07 & 19 & -46 & -49 & -42 \\
\hline Amazonas & 136 & 72 & 209 & 284 & 159 & 433 & 22 & 12 & 35 & 12 & 07 & 19 & -46 & -50 & -40 \\
\hline Bahia & 1383 & 753 & 2126 & 2163 & 1229 & 3284 & 22 & 12 & 34 & 14 & 08 & 21 & -38 & -42 & -32 \\
\hline Ceará & 652 & 355 & 1016 & 1314 & 722 & 2021 & 17 & 09 & 26 & 13 & 07 & 20 & -21 & -29 & -12 \\
\hline Distrito Federal & 118 & 64 & 181 & 241 & 136 & 369 & 31 & 17 & 47 & 14 & 08 & 21 & -55 & -58 & -52 \\
\hline Espírito Santo & 360 & 193 & 559 & 523 & 292 & 794 & 36 & 19 & 56 & 13 & 07 & 20 & -64 & -67 & -60 \\
\hline Goiás & 372 & 200 & 575 & 794 & 440 & 1221 & 28 & 15 & 43 & 13 & 07 & 20 & -53 & -56 & -49 \\
\hline Maranhão & 406 & 221 & 631 & 845 & 466 & 1316 & 18 & 10 & 27 & 14 & 08 & 21 & -21 & -27 & -14 \\
\hline Mato Grosso & 163 & 87 & 256 & 356 & 199 & 548 & 27 & 14 & 42 & 13 & 07 & 21 & -50 & -54 & -44 \\
\hline Mato Grosso do Sul & 207 & 111 & 320 & 413 & 228 & 636 & 31 & 16 & 47 & 16 & 09 & 25 & -47 & -50 & -44 \\
\hline Minas Gerais & 2349 & 1258 & 3640 & 3046 & 1677 & 4675 & 31 & 17 & 49 & 12 & 07 & 19 & -61 & -63 & -59 \\
\hline Pará & 439 & 229 & 677 & 841 & 467 & 1286 & 25 & 13 & 39 & 14 & 08 & 20 & -44 & -49 & -38 \\
\hline Paraíba & 479 & 266 & 731 & 791 & 431 & 1219 & 22 & 12 & 33 & 17 & 09 & 26 & -23 & -31 & -14 \\
\hline Paraná & 1352 & 723 & 2089 & 1900 & 1045 & 2892 & 40 & 22 & 62 & 16 & 09 & 25 & -60 & -62 & -57 \\
\hline Pernambuco & 1213 & 644 & 1851 & 1768 & 975 & 2709 & 33 & 18 & 50 & 19 & 10 & 28 & -43 & -48 & -38 \\
\hline Piauí & 263 & 144 & 406 & 512 & 284 & 773 & 21 & 11 & 32 & 14 & 08 & 21 & -32 & -38 & -25 \\
\hline Rio de Janeiro & 3369 & 1813 & 5170 & 3883 & 2127 & 5928 & 44 & 23 & 67 & 18 & 10 & 20 & -58 & -61 & -55 \\
\hline Rio Grande do Norte & 313 & 173 & 479 & 552 & 308 & 838 & 20 & 11 & 31 & 15 & 08 & 22 & -28 & -35 & -19 \\
\hline Rio Grande do Sul & 1860 & 998 & 2886 & 2269 & 1239 & 3463 & 37 & 20 & 57 & 15 & 08 & 24 & -58 & -60 & -55 \\
\hline Rondônia & 78 & 41 & 121 & 203 & 110 & 314 & 34 & 18 & 53 & 16 & 09 & 25 & -51 & -57 & -45 \\
\hline Roraima & 11 & 06 & 16 & 38 & 20 & 58 & 33 & 18 & 50 & 16 & 09 & 25 & -51 & -57 & -44 \\
\hline São Paulo & 5757 & 3104 & 8882 & 7568 & 4155 & 11,619 & 38 & 20 & 59 & 16 & 09 & 24 & -60 & -62 & -57 \\
\hline Santa Catarina & 655 & 346 & 1012 & 1001 & 552 & 1520 & 36 & 19 & 55 & 15 & 08 & 22 & -59 & -62 & -56 \\
\hline Sergipe & 177 & 97 & 268 & 297 & 166 & 452 & 22 & 12 & 33 & 15 & 08 & 22 & -33 & -38 & -28 \\
\hline Tocantins & 69 & 37 & 109 & 176 & 96 & 267 & 28 & 15 & 43 & 14 & 07 & 21 & -50 & -56 & -45 \\
\hline
\end{tabular}

U.I. uncertainty interval

*Age-standardized rate (per 100,000 inhabitants)

†Breast cancer, colorectal cancer, diabetes mellitus, ischemic heart disease, and stroke

The age-standardized mortality rate (per 100,000 population) for all causes attributable to physical inactivity in 1990 and 2017 in the Brazilian female population was 28 (95\% U.I. 15-43) and 13 (95\% U.I. 07-20), respectively. In 2017, there was a significant reduction compared to 1990 in age-standardized mortality rate for all causes attributable to physical inactivity in females from all Brazilian states. While in 1990, the highest agestandardized mortality rates for all causes attributable to physical inactivity were observed in females from the Midwest, Southern, and Southeastern states of Brazil; in 2017, the highest age-standardized mortality rates for all causes attributable to physical inactivity were observed in females from the Northeast of Brazil (Fig. 2).

The age-standardized mortality rates (per 100,000 inhabitants) for all causes attributable to physical inactivity increased as the age group of the Brazilian population increased in both sexes. In 1990, the PAF showed that approximately $1.0 \%, 3.0 \%$, and $4.0 \%$ of all-cause deaths in males aged $25-49$ years, $50-69$ years, and $\geq 70$ years, respectively, could be avoided if the Brazilian population reached 3000-4500 MET-min per week of physical activity. In 2017 , the values were $0.6 \%, 2.4 \%$, and $3.0 \%$ for males aged $25-49$ years, $50-69$ years, and $\geq 70$ years, 


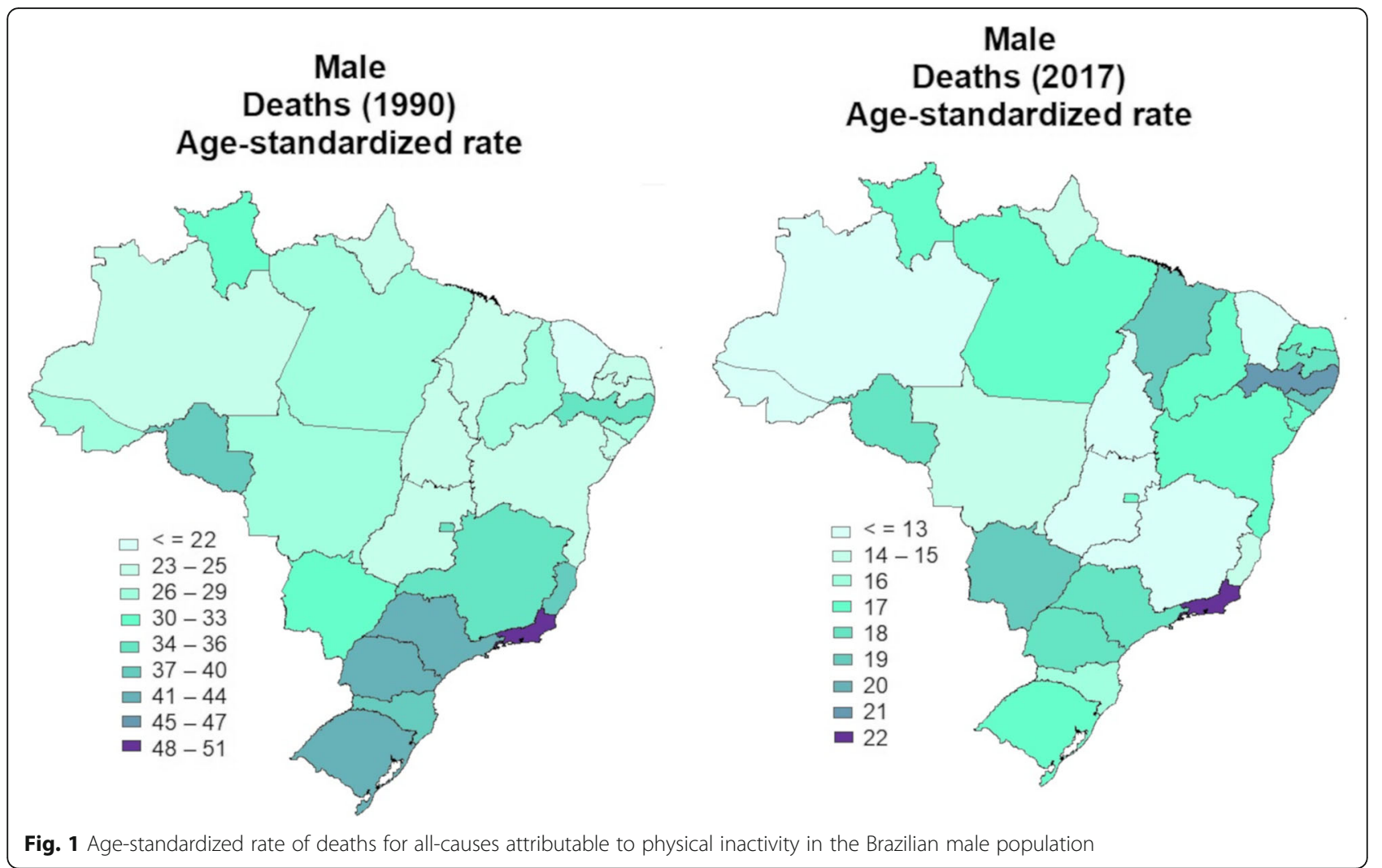

respectively. For females in 1990, the PAF showed that $1.3 \%, 3.5 \%$, and $5.1 \%$ of all-cause deaths in aged $25-49$ years, 50-69 years, and $\geq 70$ years, respectively, could be avoided if the Brazilian population reached 3000-4500 MET-min per week of physical activity. In 2017, the values were $1.1 \%, 2.6 \%$, and $3.3 \%$ for females aged $25-49$ years, $50-69$ years, and $\geq 70$ years, respectively (Table 2 ).

Figure 3 shows the relationship between the decreases in age-standardized mortality rate for all causes attributable to physical inactivity with the SDI of the Brazilian states. The Brazilian states with better socioeconomic conditions presented greater reductions in age-standardized mortality for all-causes due to physical inactivity (male: rho $=0.80$; female: rho 0.84 ) rates over the period of 28 years.

\section{Discussion}

In this study, from 1990 to 2017, a decrease in standardized death rate from all causes attributable to physical inactivity was observed in Brazil. This result demonstrates Brazil's progress in this scenario. At least three hypotheses could be given to explain these results. The first hypothesis is that the Brazilian population is more physically active compared to the 1990s, and therefore, there was a decrease in standardized death rate from all causes attributable to physical inactivity. To illustrate this hypothesis, a survey conducted from 2006 to 2016 in all states of Brazil aimed to analyze time trends in leisure-time physical activity in adults [17]. The authors found that there was an increase both in the percentage of leisure-time physical activity (from 44.0 to $53.6 \%$ or 0.97 percentage points per year) and in the percentage of individuals that achieved recommended levels of physical activity (i.e., $\geq 150 \mathrm{~min} /$ week), from 30.3 to $37.6 \%$ (1.20 percentage points per year) [17]. However, this study cited found this increase considering physical activity during leisure time.

This study showed an important metric in global health estimates (i.e., SEV) that does not fully accept the first hypothesis. Information about SEV revealed that the risk of the Brazilian population have been exposed to physical inactivity was stable over 28 years (SEV = $59 \%$ in 1990, and SEV $=59 \%$ in 2017). One of the factors that justify this stability is the urban and technological development that Brazil has undergone during these 28 years, resulting in less involvement in daily physical activities and greater propensity for physically inactive lifestyles $[7,18]$.

The second hypotheses that could explain the reduction in age-standardized mortality rates for all causes attributable to physical inactivity from 1990 to 2017 in Brazil are the successful actions for prevention, diagnosis, and treatment of chronic noncommunicable diseases 


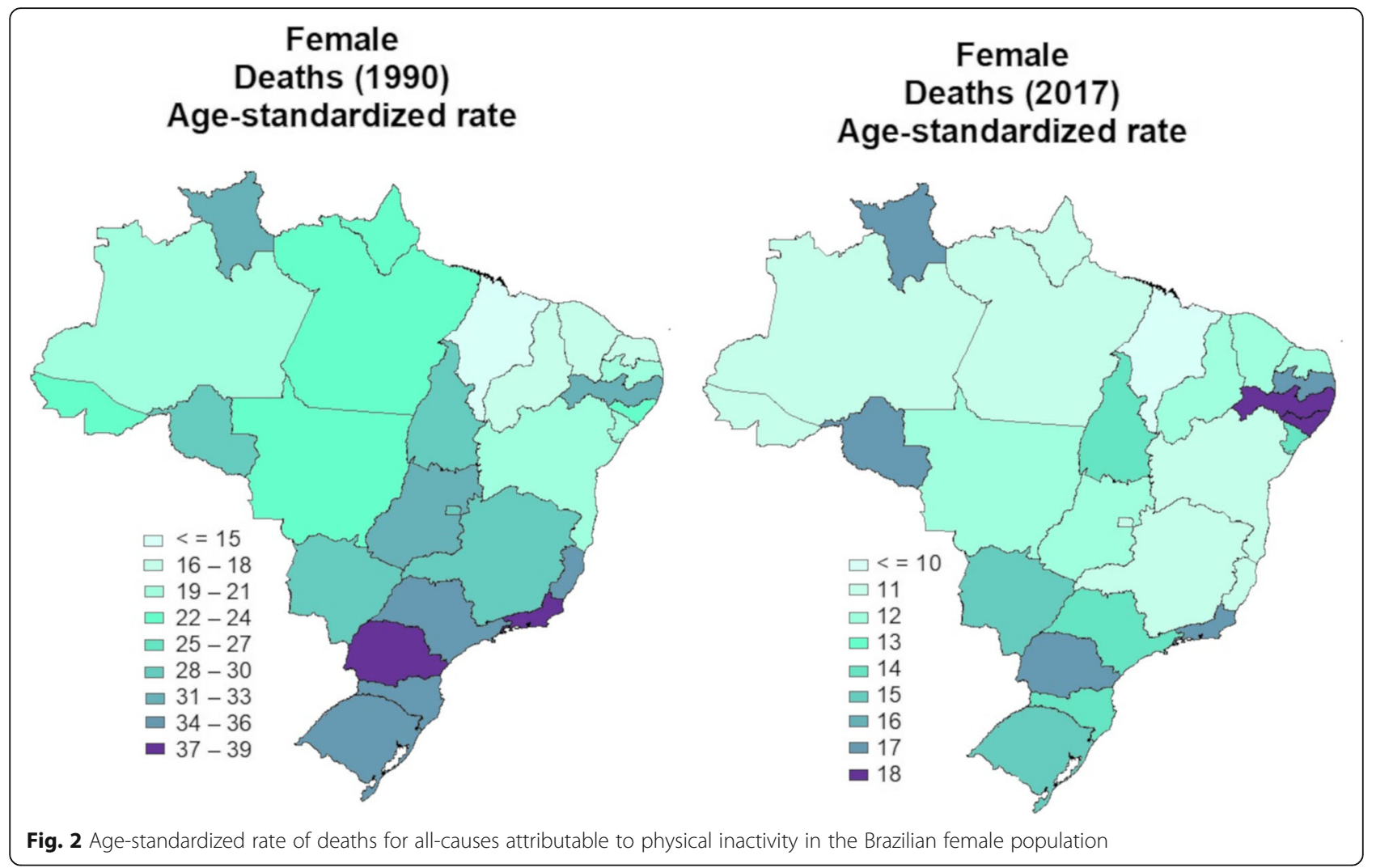

in Brazil over almost three decades. A research conducted in all states of Brazil aimed to analyze the mortality trends for chronic noncommunicable diseases in the period 2000-2013 and its probability of death until 2025 [19]. The authors found that there was an average decline of $2.5 \%$ per year in all four major chronic noncommunicable diseases in Brazil (i.e., cardiovascular diseases; respiratory diseases; malignant neoplasms; diabetes mellitus), and the probability of premature death was reduced from $30 \%$ in 2000 to $26.1 \%$ in 2013 , and it was estimated that this probability reduces to $20.5 \%$ in 2025 [19]. In addition, Brazil has wellestablished policies to combat chronic noncommunicable diseases since 2011 [20].

The second hypothesis presented above may not be fully accepted if one analyzes the trends in age-

Table 2 Age-standardized mortality rate and the population attributable fraction in Brazilian population

\begin{tabular}{|c|c|c|c|c|}
\hline & \multicolumn{4}{|c|}{ Mortality due to all-causes ${ }^{\dagger}$ attributable to physical inactivity } \\
\hline & \multicolumn{2}{|l|}{ Male } & \multicolumn{2}{|l|}{ Female } \\
\hline & Rate $^{*}(95 \%$ U.I.) & PAF: \% (95\% U.I.) & Rate* $^{*} 95 \%$ U.I.) & PAF: \% (95\% U.I.) \\
\hline \multicolumn{5}{|l|}{1990} \\
\hline 25-49 years & $3.2(1.6-5.1)$ & $0.8(0.4-1.4)$ & $2.0(1.0-2.8)$ & $1.3(0.7-2.0)$ \\
\hline $50-69$ years & $58.8(31.4-92.6)$ & $3.2(1.7-5.0)$ & $37.0(20.2-56.7)$ & $3.5(1.9-5.3)$ \\
\hline$\geqq 70$ years & $311.7(166.7-480.6)$ & $4.1(2.2-6.4)$ & $310.2(167.8-473.8)$ & $5.1(2.8-7.8)$ \\
\hline \multicolumn{5}{|l|}{2017} \\
\hline 25-49 years & $1.9(0.9-3.1)$ & $0.6(0.3-1.0)$ & $1.2(0.6-1.9)$ & $1.1(0.6-1.7)$ \\
\hline $50-69$ years & $32.3(17.2-50.7)$ & $2.4(1.3-3.8)$ & $19.6(10.9-29.7)$ & $2.6(1.4-3.9)$ \\
\hline$\geqq 70$ years & $183.8(101.9-282.3)$ & $3.0(1.7-3.8)$ & $166.3(92.6-251.5)$ & $3.3(1.8-5.0)$ \\
\hline
\end{tabular}

PAF population attributable fraction, U.I. uncertainty interval

*Rate per 100.000 inhabitants

†Breast cancer, colorectal cancer, diabetes mellitus, ischemic heart disease, and stroke 

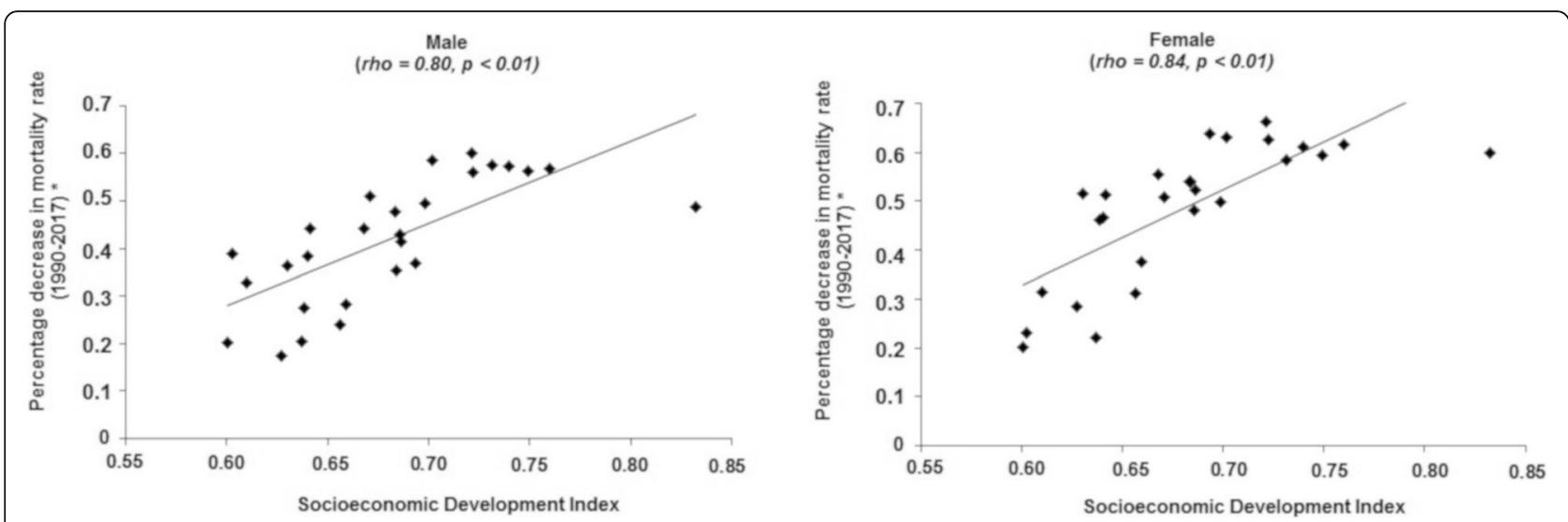

Fig. 3 Relationship between percentage decrease in age-standardized rate of deaths due to physical inactivity and SDI. Note, age-standardized rate; rho, Spearman's correlation coefficient

standardized mortality rate from breast cancer, colorectal cancer, ischemic heart disease, diabetes mellitus, and stroke in Brazil. These five causes of mortality were those studied in the present study as attributable to physical inactivity. The study of breast cancer mortality trends revealed that there was stability in agestandardized mortality rate from 1990 to 2015 in Brazilian women [21]. For colorectal cancer, there was an increased in age-standardized mortality rate from 1990 to 2015 in men in Brazil, and there was a stability in women [21]. For stroke [22], ischemic heart disease [23], and diabetes mellitus [24], there was decreased in age-standardized mortality rate from 1990 to 2015 in men and women in Brazil.

The third hypothesis to explain the reduction in agestandardized mortality rates for all causes observed in the present study and that seems to explain, in part, these results is the fact that Brazil has been successful in reducing other risk factors for noncommunicable chronic diseases $[25,26]$. The prevalence of smokers in Brazil dropped 0.65 points percentage per year from 2006 (15.6\%) to $2014(10.8 \%)$ [25]. In addition, from 2008 to 2015, there was an increase in the consumption of fruits and vegetables in the Brazilian population [26]. These risk factors are also related to the diseases investigated in the present study (i.e., stroke, breast cancer, colorectal cancer, ischemic heart disease, and diabetes mellitus), and this can interfere with the estimation models of mortality.

Thus, it seems to be more cautious to state that a combination of the first, second, and third hypothesis presented justifies the findings of the present study. For, while at the same time that actions of prevention, diagnosis, and treatment of chronic noncommunicable diseases in Brazil were implemented [20], policies of promotion of the physical activity were implemented [27].
These efforts are needed to decrease mortality by noncommunicable chronic diseases.

The present study found that from 1990 to 2017, Brazilian states with the lowest SDI and with the greatest social discrepancies had lower reductions in agestandardized mortality rates for all causes due to physical inactivity when compared to states with better economic development. This finding reinforces two problems that have already been presented in literature [18, 28]: (1) physical inactivity is a serious problem in economically disadvantaged populations; (2) social and economic inequalities present in these states are reflecting on the health of the population, causing greater difficulty in reducing physical inactivity. Thus, increasing the level of physical activity of the population in order to reduce the risks of early mortality and morbidity due to noncommunicable chronic diseases should include efforts to improve the living conditions and reduce inequities of the population and not only isolated physical activity promotion actions.

This study corroborates what was demonstrated in a previous study [1] in which mortality due to physical inactivity was greater as the age group increases. The aging process alone leads to an increased risk of chronic diseases and noncommunicable chronic diseases and a reduction in daily physical activities $[1,7,18]$, which makes it clear that initiatives to promote active and healthy aging should be prominent in Brazil.

The fact that this study considers only the outcome information on stroke, breast cancer, colorectal cancer, ischemic heart disease, and diabetes mellitus is a limitation. Although there is consistent evidence that physical inactivity is an independent risk factor for these diseases [3], there is also some evidence for other health problems and chronic diseases [29], which were not considered in the present study. Because of this, it is likely that 
the burden of disease associated with physical inactivity is underestimated. The other limitation of this study includes the measurement of physical activity through different questionnaires that although result in an estimate of the level of physical activity, can also result in error and bias resulting from different forms of interpretation, different questionnaires, and possibly social desirable responses. In addition, a questionnaire is a subjective measure of physical activity. The other limitation of this study is the non-stratification of physical activity by different domains so that a deeper knowledge of the different physical activity patterns would be presented. Another limitation evident in this research is that the 95\% U.I. for the age-standardized SEV is very large, and therefore, it is difficult to draw conclusions on this.

\section{Conclusions}

It could be concluded that physical inactivity contributed to a substantial number of deaths in Brazil and in the different Brazilian states from 1990 to 2017. From 1990 to 2017 , a decrease in standardized death rate from all causes attributable to physical inactivity was observed in Brazil. Brazilian states with the highest social inequalities showed lower reductions (from 1990 to 2017) in agestandardized mortality rate for all causes attributable to physical inactivity. The results of the present study show the importance of preventing risk factors for noncommunicable chronic diseases in all Brazilian states, and greater effort in combating social and economic inequities related to the living conditions of the population is needed, so that the adoption of active and healthy lifestyle has greater reach in all regions of Brazil.

\section{Abbreviations \\ DALYs: Disability-adjusted life-years; GBD: Global Burden of Disease; GPAQ: Global Physical Activity Questionnaire; IHME: Institute for Health Metrics and Evaluation; IPAQ: International Physical Activity Questionnaire; PAF: Population attributable fraction; SDI: Socioeconomic Development Index; SEV: Summary exposure value; ST-GPR: Spatiotemporal Gaussian process regression; TMREL: Theoretical minimum-risk exposure level; U.I.: Uncertainty intervals}

\section{Acknowledgements}

Not applicable

\section{About this supplement \\ This article has been published as part of Population Health Metrics, Volume 18 Supplement 1 2020: The GBD Brazil Network. The full contents of the supplement are available at https://pophealthmetrics.biomedcentral.com/ articles/supplements/volume-18-supplement-1.}

\section{Authors' contributions}

DASS designed the study. DASS analyzed the data and produced the manuscript. MST, EC, BRN, and PFVN interpreted the data. FM, ALPR, MN, and DM directed the study. All authors contributed to the editing of the manuscript and agreed the final text.

Authors' information

Not applicable

\section{Funding}

Publication costs are funded by Brazilian Ministry of Health through resource transfer from the National Health Fund (TED - 125/2017).

\section{Availability of data and materials}

Data we used in this article are publicly available online on the official website of Institute of Health Metrics and Evaluation (http://ghdx.healthdata. org/gbd-results-tool).

\section{Ethics approval and consent to participate}

The Project "Global Burden of Diseases - GBD in Brasil" was approved by the Research Ethics Committee from the Universidade Federal de Minas Gerais (UFMG), under protocol number 62803316.7.0000.5149.

\section{Consent for publication}

Not applicable

\section{Competing interests}

The authors declare that they have no competing interests.

\section{Author details}

${ }^{1}$ Physical Education Department, Research Center in Kinanthropometry and Human Performance, Federal University of Santa Catarina, Trindade, Florianopolis, SC 88040-900, Brazil. ${ }^{2}$ Children's Hospital of Eastern Ontario Research Institute, Ottawa, ON, Canada. ${ }^{3}$ Department of Health Surveillance, Ministry of Health, Brasília, DF, Brazil. ${ }^{4}$ Federal University of Minas Gerais, Belo Horizonte, MG, Brazil. ${ }^{5}$ Graduate Program of Epidemiology, Federal University of Rio Grande do Sul, Porto Alegre, RS, Brazil. ${ }^{6}$ Clinical Hospital of the Federal University of Minas Gerais, Belo Horizonte, MG, Brazil. 'Institute for Health Metrics and Evaluation, Seattle, WA, USA.

Received: 9 June 2020 Accepted: 9 July 2020

Published: 30 September 2020

\section{References}

1. Lee IM, Shiroma EJ, Lobelo F, Puska P, Blair SN, Katzmarzyk PT. Lancet Physical Activity Series Working Group. Effect of physical inactivity on major non-communicable diseases worldwide: an analysis of burden of disease and life expectancy. Lancet. 2012;380(9838):219-29.

2. Ekelund U, Steene-Johannessen J, Brown WJ, Fagerland MW, Owen N, Powell KE, Bauman A. Lee IM; Lancet Physical Activity Series 2 Executive Committe; Lancet Sedentary Behaviour Working Group. Does physical activity attenuate, or even eliminate, the detrimental association of sitting time with mortality? A harmonised meta-analysis of data from more than 1 million men and women. Lancet. 2016;388(10051):1302-10.

3. Kyu HH, Bachman VF, Alexander LT, Mumford JE, Afshin A, Estep K, Veerman $J \mathrm{~L}$, Delwiche K, lannarone ML, Moyer ML, Cercy K, Vos T, Murray CJ, Forouzanfar MH. Physical activity and risk of breast cancer, colon cancer, diabetes, ischemic heart disease, and ischemic stroke events: systematic review and dose-response meta-analysis for the Global Burden of Disease Study 2013. BMJ. 2016;354:13857.

4. Morris JN, Heady JA, Raffle PA, Roberts CG, Parks JW. Coronary heart-disease and physical activity of work. Lancet. 1953;265(6795):1053-7.

5. Global Burden of Disease Risk Factors Collaborators. Global, regional, and national comparative risk assessment of 84 behavioural, environmental and occupational, and metabolic risks or clusters of risks for 195 countries and territories, 1990-2017: a systematic analysis for the Global Burden of Disease Study 2017. Lancet. 2018;392(10159):1923-1994.

6. Andersen LB, Mota J, Di Pietro L. Update on the global pandemic of physical inactivity. Lancet. 2016;388(10051):1255-6.

7. Guthold R, Stevens GA, Riley LM, Bull FC. Worldwide trends in insufficient physical activity from 2001 to 2016: a pooled analysis of 358 populationbased surveys with 1.9 million participants. Lancet Glob Health. 2018;6(10): e1077-86.

8. World Health Organization. Global action plan on physical activity 20182030: more active people for a healthier world. Geneva: WHO; 2018.

9. Rezende LF, Rabacow FM, Viscondi JY, Luiz Odo C, Matsudo VK, Lee IM. Effect of physical inactivity on major noncommunicable diseases and life expectancy in Brazil. J Phys Act Health. 2015;12(3):299-306.

10. Ramalho JR, Mambrini JV, César CC, Oliveira CM, Firmo JO, Lima-Costa MF, Peixoto SV. Physical activity and all-cause mortality among older Brazilian 
adults: 11-year follow-up of the Bambuí Health and Aging Study. Clin Interv Aging. 2015;10:751-8.

11. Silva DAS, Tremblay MS, Souza MFM, Mooney M, Naghavi M, Malta DC. Mortality and years of life lost by colorectal cancer attributable to physical inactivity in Brazil (1990-2015): findings from the Global Burden of Disease Study. PLoS One. 2018;13(2):e0190943.

12. Silva DAS, Tremblay MS, Souza MFM, Guerra MR, Mooney M, Naghavi M, Malta DC. Mortality and years of life lost due to breast cancer attributable to physical inactivity in the Brazilian female population (1990-2015). Sci Rep. 2018:8(1):11141.

13. Global Burden of Disease DALYs and HALE Collaborators. Global, regional, and national disability-adjusted life-years (DALYs) for 359 diseases and injuries and healthy life expectancy (HALE) for 195 countries and territories, 1990-2017: a systematic analysis for the Global Burden of Disease Study 2017. Lancet. 392: 1859-922, 2018

14. Global Burden of Disease Causes of Death Collaborators. Global, regional, and national age-sex-specific mortality for 282 causes of death in 195 countries and territories, 1980-2017: a systematic analysis for the Global Burden of Disease Study 2017. Lancet. 392: 1736-1788, 2018.

15. Global Burden of Disease Mortality Collaborators. Global, regional, and national age-sex-specific mortality and life expectancy, 1950-2017: a systematic analysis for the Global Burden of Disease Study 2017. Lancet. 392:1684-1735, 2018.

16. World Health Organization. Global recommendations on physical activity for health. Geneva: World Health Organization; 2010

17. Cruz MSD, Bernal RTI, Claro RM. Trends in leisure-time physical activity in Brazilian adults (2006-2016). Cad Saude Publica. 2018;34(10):e00114817.

18. Hallal PC, Andersen LB, Bull FC, Guthold R, Haskell W. Ekelund U; Lancet Physical Activity Series Working Group. Global physical activity levels: surveillance progress, pitfalls, and prospects. Lancet. 2012;380(9838):247-57.

19. Malta DC, Andrade SS, Oliveira TP, Moura L, Prado RR, Souza MFM. Probability of premature death for chronic non-communicable diseases, Brazil and Regions, projections to 2025. Rev Bras Epidemiol. 2019;22:e190030.

20. Malta DC, Morais Neto OL, Silva Junior JB. Presentation of the strategic action plan for coping with chronic diseases in Brazil from 2011 to 2022. Epidemiol Serv Saúde. 2011;20(4):425-38.

21. Guerra MR, Bustamante-Teixeira MT, Corrêa CSL, Abreu DMX, Curado MP, Mooney M, Naghavi M, Teixeira R, França EB, Malta DC. Magnitude and variation of the burden of cancer mortality in Brazil and Federation Units, 1990 and 2015. Rev Bras Epidemiol. 2017;20(Suppl 1):102-15.

22. Lotufo PA, Goulart AC, Passos VMA, Satake FM, Souza MFM, França EB, Ribeiro ALP, Bensenör IJM. Cerebrovascular disease in Brazil from 1990 to 2015: Global Burden of Disease 2015. Rev Bras Epidemiol. 2017;20(Suppl 1):129-41.

23. Brant LCC, Nascimento BR, Passos VMA, Duncan BB, Bensenõr IJM, Malta DC, Souza MFM, Ishitani LH, França E, Oliveira MS, Mooney M, Naghavi M, Roth G, Ribeiro ALP. Variations and particularities in cardiovascular disease mortality in Brazil and Brazilian states in 1990 and 2015: estimates from the Global Burden of Disease. Rev Bras Epidemiol. 2017;20(Suppl 1):116-28.

24. Duncan BB, França EB, Passos VMA, Cousin E, Ishitani LH, Malta DC, Mohsen $\mathrm{N}$, Mooney M, Schmidt MI. The burden of diabetes and hyperglycemia in Brazil and its states: findings from the Global Burden of Disease Study 2015. Rev Bras Epidemiol. 2017;20(Suppl 1):90-101.

25. Malta DC, Stopa SR, Santos MAS, Andrade SSCA, Oliveira TP, Cristo EB, Silva MMAD. Evolution of tobacco use indicators according to telephone surveys, 2006-2014. Cad Saude Publica. 2017:33(Suppl 3):e00134915.

26. Malta DC, Bernal RTI, Vieira Neto E, Curci KA, Pasinato MTM, Lisbôa RM, Cachapuz RF, Coelho KSC. Trends in risk and protective factors for noncommunicable diseases in the population with health insurance in Brazil from 2008 to 2015. Rev Bras Epidemiol. 2018;21(Suppl 1):e180020.

27. Brasil. Ministério da Saúde. Secretaria de Vigilância em Saúde. Departamento de Análise de Situação de Saúde. Plano de ações estratégicas para o enfrentamento das doenças crônicas não transmissíveis (DCNT) no Brasil 2011-2022. Braślia: Secretaria de Vigilância em Saúde/Departamento de Análise de Situação de Saúde; 2011.

28. Silva DAS, Malta DC, Souza MFM, Naghavi M. Burden of ischemic heart disease mortality attributable to physical inactivity in Brazil. Rev Saude Publica. 2018;52:72.

29. U.S. Department of Health and Human Services (USDHHS), 2018 Physica Activity Guidelines Advisory Committee. 2018 Physical activity guidelines advisory committee scientific report. Washington, DC: USDHHS, 2018.

\section{Publisher's Note}

Springer Nature remains neutral with regard to jurisdictional claims in published maps and institutional affiliations.
Ready to submit your research? Choose BMC and benefit from:

- fast, convenient online submission

- thorough peer review by experienced researchers in your field

- rapid publication on acceptance

- support for research data, including large and complex data types

- gold Open Access which fosters wider collaboration and increased citations

- maximum visibility for your research: over $100 \mathrm{M}$ website views per year

At BMC, research is always in progress.

Learn more biomedcentral.com/submissions 